\title{
Erratum to: Is the ADA/EASD algorithm for the management of type 2 diabetes (January 2009) based on evidence or opinion? A critical analysis
}

\author{
G. Schernthaner - A. H. Barnett • D. J. Betteridge $\cdot$ R. Carmena • A. Ceriello • \\ B. Charbonnel • M. Hanefeld $\cdot$ R. Lehmann • M. T. Malecki $\cdot$ R. Nesto $\cdot$ V. Pirags • \\ A. Scheen • J. Seufert • Å. Sjöholm • A. Tsatsoulis • R. DeFronzo
}

Published online: 25 May 2010

(C) Springer-Verlag 2010

Erratum to: Diabetologia

DOI 10.1007/s00125-010-1702-3

Unfortunately, 'A. Sjöholm' was spelt incorrectly in the author list on the original version.

The online version of the original article can be found at http://dx.doi. org/10.1007/s00125-010-1702-3.

\section{G. Schernthaner $(\triangle)$}

Department of Medicine I, Rudolfstiftung Hospital-Vienna,

Juchgasse 25,

1030 Vienna, Austria

e-mail: guntram.schernthaner@meduniwien.ac.at

\section{A. H. Barnett}

University of Birmingham and Heart of England NHS Trust,

Birmingham, UK

\section{J. Betteridge}

University College London Hospitals,

London, UK

R. Carmena

University of Valencia,

Valencia, Spain

\section{A. Ceriello}

Department of Endocrinology, University of Udine,

Udine, Italy

B. Charbonnel

University Hospital,

Nantes, France

\section{Hanefeld}

Center for Clinical Studies, GWT Dresden,

Dresden, Germany

\section{R. Lehmann}

University Hospital Zurich,

Zurich, Switzerland
In addition, the following text was omitted from the Duality of interest section: $\AA$. Sjöholm has received lecture fees and honoraria for advisory boards from Eli Lilly, Merck, NovoNordisk, sanofi-aventis, Novartis and GlaxoSmithKline. R. Carmena has received lecture fees and honoraria for advisory boards from MSD, Pfizer, AstraZeneca and Takeda.

M. T. Malecki

Jagiellonian University,

Krakow, Poland

R. Nesto

Lahey Clinic Medical Center,

Burlington, MA, USA

V. Pirags

University of Latvia,

Riga, Latvia

A. Scheen

CHU Sart Tilman, University of Liège,

Liège, Belgium

J. Seufert

University Hospital of Freiburg,

Freiburg, Germany

Å. Sjöholm

Karolinska Institutet,

Stockholm, Sweden

A. Tsatsoulis

University of Ioannina,

Ioannina, Greece

R. DeFronzo

University of Texas Health Science Center,

San Antonio, TX, USA 